\title{
Título: Emociones en la actividad físico deportiva
}

Autores: Lidia Guerrero Arana

Mercedes Sicardo Anaya

Esperanza Vital Tejero

"La educación en valores y la práctica de actividad física en colectivos de desigualdad". Grado de Ciencias de la Actividad Física y del Deporte. Universidad de Huelva

Email: lidia_guerrero14@hotmail.com 


\section{Emociones en la actividad}

Profesor:

Pedro Sáenz.-López Buñuel

\section{Autores:}

\section{ÍNDICE}

- Lidia Guerrero Arana

- Mercedes Sicardo Anaya

- Esperanza Vital Tejero
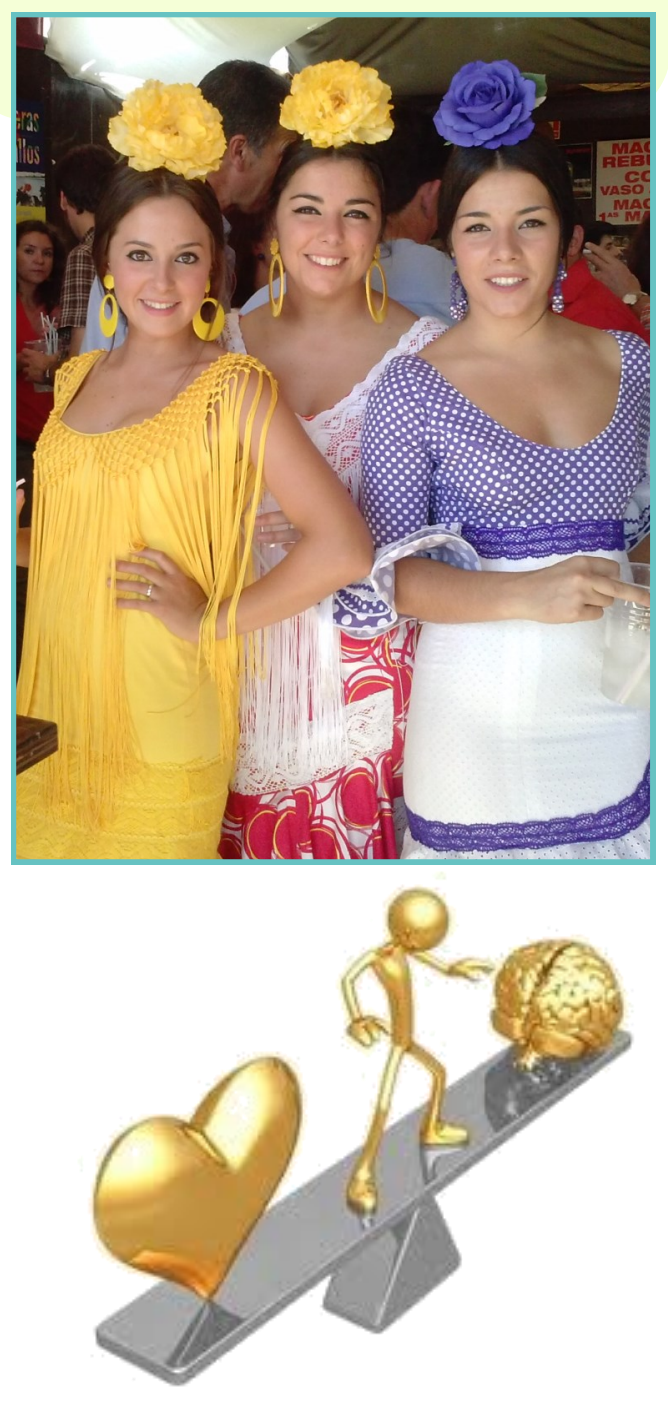

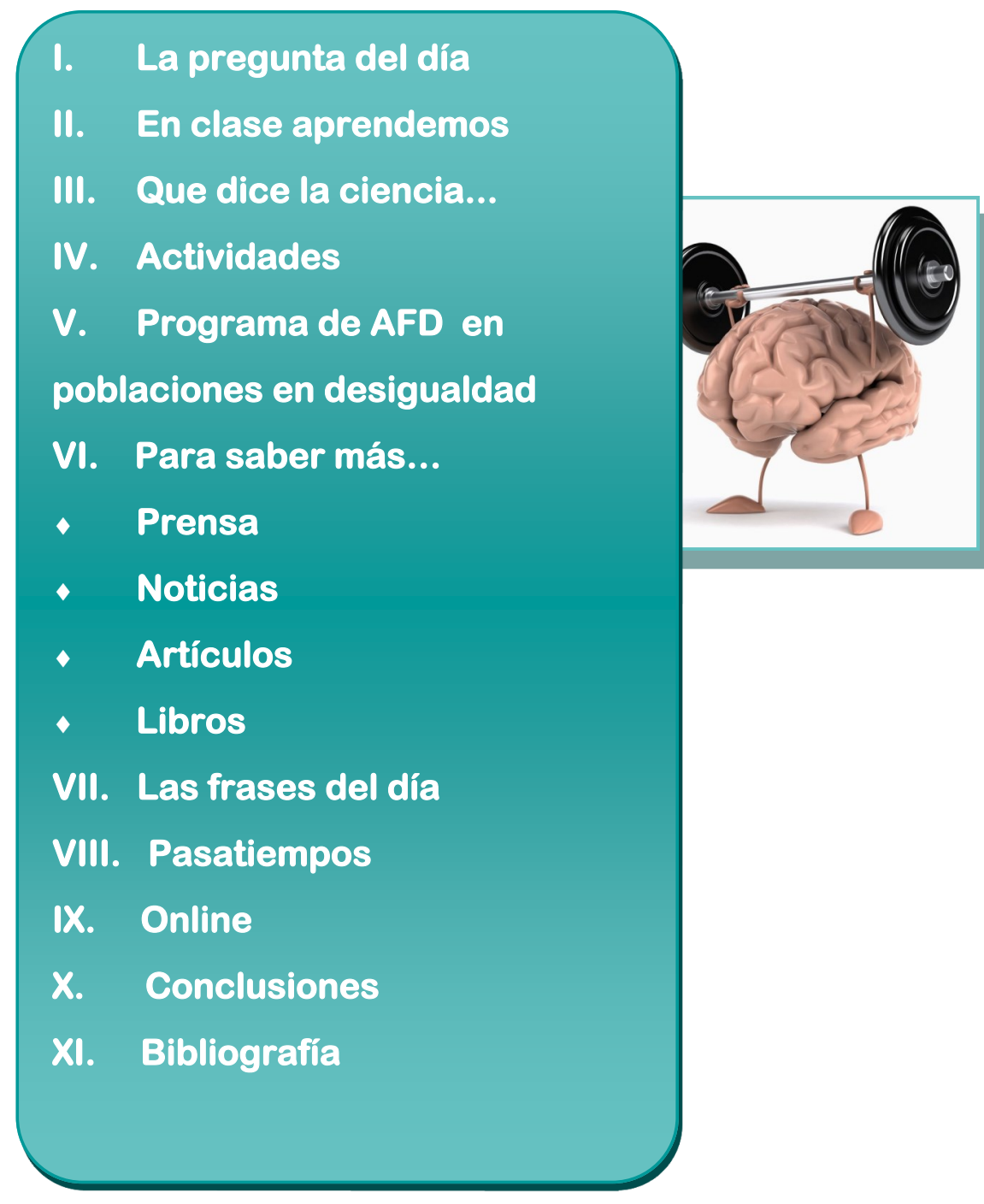




\section{EDITORIAL}

Las emociones nos acompañan a lo largo de toda nuestra vida desde que nacemos. Sería fundamental poner nombre a lo que sentimos en cada momento para así afrontar las emociones negativas y potenciar las positivas. Podemos decir que todas las emociones son útiles. Además a las personas nos cuesta hablar de lo que sentimos y reconocer nuestras emociones, podríamos considerarlo una asignatura pendiente que podemos aprender.

Sería de gran interés preguntarnos ¿qué sentimos y qué emociones tenemos en cada momento?

Se puede considerar la educación emocional como la raíz de la educación en valores y el conocimiento de las emociones en la AFD parte del desarrollo de la Inteligencia Emocional.

En nuestro campo de actuación es fundamental emocionar a través de las AFD y así preguntarnos ¿qué emociones nos desata la práctica de actividad física?

\section{La pregunta del día...}
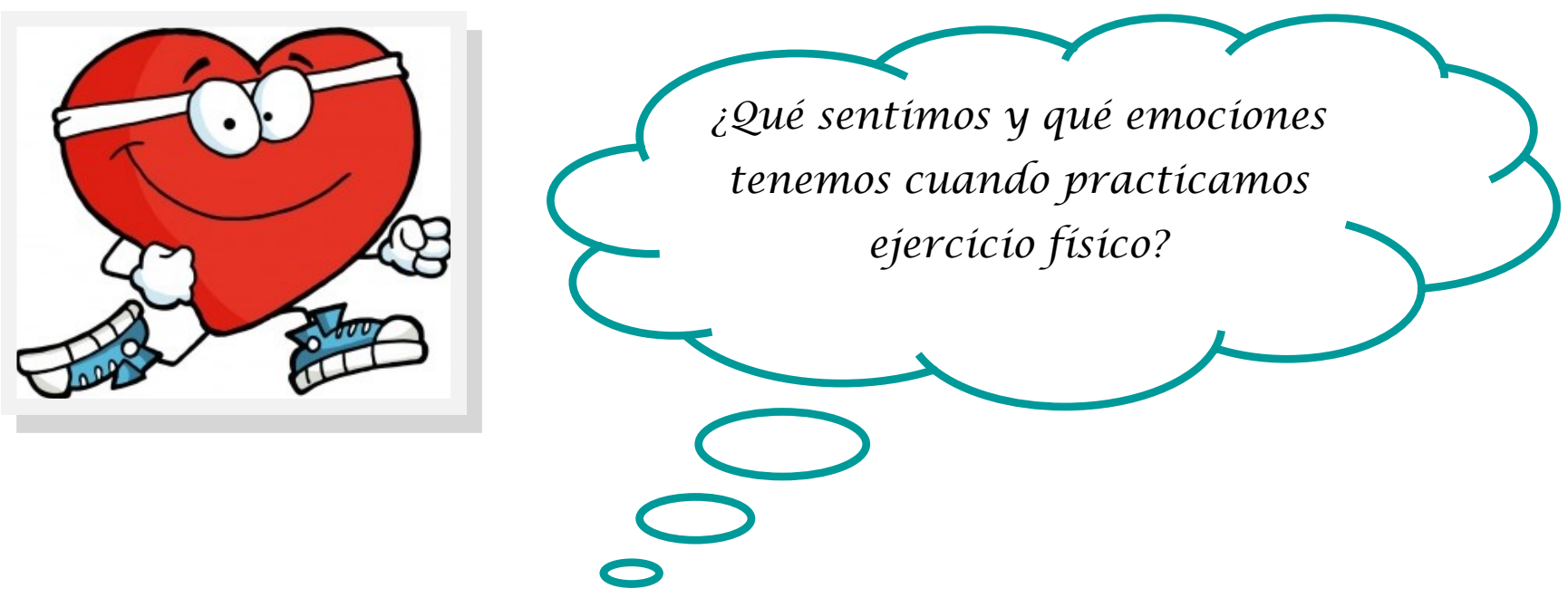


\section{En clase aprendemos...}

\section{¿Qué es la praxeología?}

Según Sáenz-López (20I4), la praxeología es la ciencia que estudia la conducta motriz. Debemos conocerla ya que forma parte del ámbito de la actividad física y del deporte y nos favorece porque el objeto de conocimiento es la motricidad.

Esta ciencia aporta mucho al deporte y se considera CURIOSIDADES una fuente de información para la práctica

Los especialistas en la ciencias de la AFD, normalmente, no se consideran praxeólogos porque usan, además de la praxeología, otras muchas ciencias como la sociología, la fisiología...

TIPOS DE ACTIVIDAD FÍSICA 


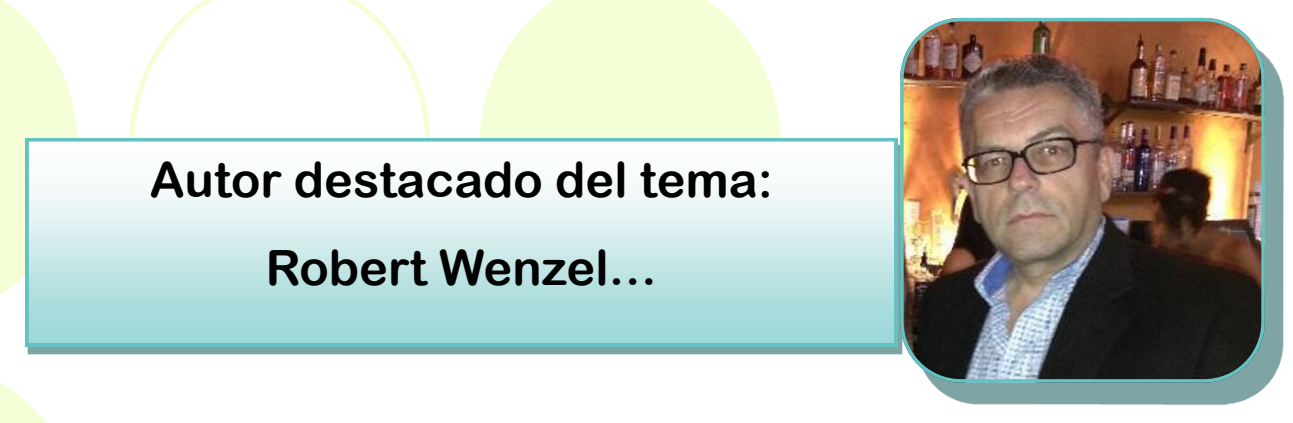

Según Robert Wenzel, la praxeología se basa en el axioma fundamental de que los seres humanos actúan, es decir, en el hecho primordial de que los individuos realizan acciones conscientes hacia objetivos elegidos.

En el mundo todas las acciones tienen un lugar en el tiempo, comenzando con el presente y dirigiéndose hacia el futuro, alcanzando un fin (inmediato o remoto). Si se pudieran conseguir instantáneamente todos los deseos, no habría ninguna razón para actuar. Además, el que un hombre actúe implica que cree que la acción supondrá una diferencia. La acción implica que el hombre no tiene un conocimiento omnisciente del futuro, pero si lo tuviera, ninguna acción suya supondría ninguna diferencia, lo que conlleva a la incertidumbre.

El hecho de que la gente actúa implica necesariamente que los medios empleados son escasos en relación con los fines deseados, pues si todos los medios fueran abundantes, los fines se alcanzarían y no habría necesidad de acción.

Bibliografia: Rothbard, M (20I2). Instituto Mises Hispano [en línea]. Praxeología: la metodología de la economía austriaca. Disponible en: http://www.miseshispano.org/2012/08/praxeologia-la-metodologia-de-laeconomia-austriaca/ [Consulta: 20I4, 30 de Noviembre].

\section{Más información sobre la praxeología:}

Praxeología : Metodología

https://www.youtube.com/watch?v=7E5PHuQS7OQ

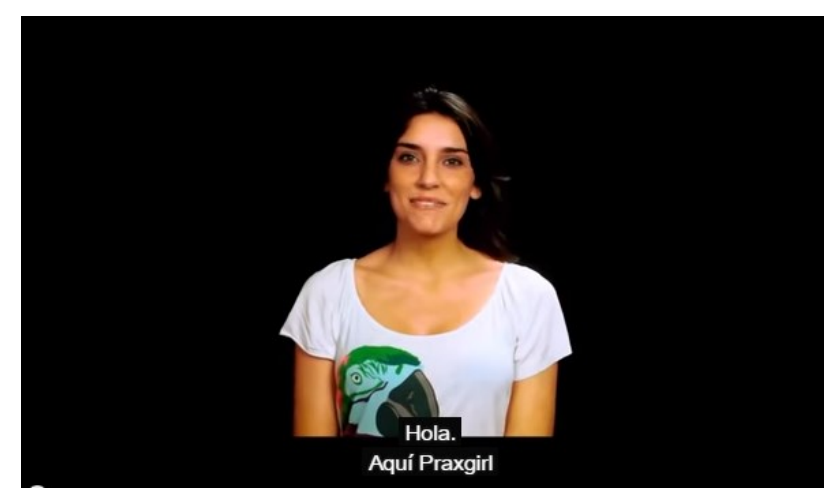


Artículo 1.

Formación emocional y juegos en futuros docentes de educación fisica.

El objetivo principal que pretende lograr este articulo es analizar del tipo de vivencia emocional que suscitan los cuatro dominios de acción motriz (juegos psicomotores, juegos de cooperación, juegos de oposición y juegos de cooperación-oposición).

Las situaciones motrices lúdicas generan vivencias positivas. Además el juego motor desarrolla un contexto social y afectivo válido para educar en emociones a los futuros docentes y dotarles de herramientas para que pueda incluir en sus programas competencias emocionales desde la motricidad. En el caso de los juegos en los que no hay oposición motriz, la competición si parece un factor a tener en cuenta para incrementar la vivencia competitiva pero para los tipos de juego en los que sí existe esta oposición no es relevante si se compite con marcador o si él.

Los futuros docentes de educación física deben tener conocimiento en educación emocional y los juegos motores deportivos son excelentes para avanzar en este sentido.

Bibliografia: Alonso, J.l., Gea, G., \& Yuste, J.L. (20I3). Formación emocional y juego en futuros docentes de educación física. Revista Electrónica Interuniversitaria de Formación del Profesorado, I6(I), 97-I08.

http://www.aufop.com/aufop/uploaded files/articulos/I375389683.pdf

\section{Artículo 2.}

Teaching motor and emotional competencies in university students

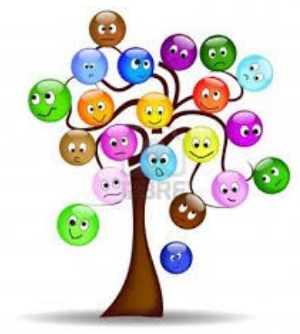

En este articulo se examina la relación entre las competencias motrices y emocionales en estudiantes de educación física producidos por diferentes juegos deportivos clasificados en cuatro dominios de acción motriz (psicomotriz, cooperación, oposición , cooperación- oposición

Se demostró que las emociones variaron considerablemente entre las competencias socio motrices y los juegos psicomotores. Esta investigación confirma el papel relevante de los juegos cuando se trata de enseñar competencias motrices y emocionales en estudiantes universitarios.

Bibliografia: Lavega, P.; Aráujo, P., y Jaqueira, A. R. (2013). Teaching motor and emotional competencies in university students. Cultura Ciencia y Deporte, 8(22), 5-15.

http://ccd.ucam.edu/index.php/revista/issue/view/48 


\section{Artículo 3.}

Understanding emotions through games: helping trainee theachers to make decitions.

El objetivo del artículo es proporcionar directrices para ayudar a los profesionales a tomar decisiones con respecto a los tipos de emociones producidas por diferentes juegos deportivos clasificados en cuatro dominios de acción motriz (psicomotriz, cooperación, oposición, cooperación-oposición).

Se compararon los diferentes dominios de acción motora y se demostró que los juegos de cooperación eran los más propensos a provocar intensas emociones positivas. En los juegos de cooperación no competitivos las puntuaciones de las emociones positivas fueron 18,3 superiores a las obtenidas en los juegos competitivos.

Los hallazgos sugirieron que el tipo de juego escogidos en la primera decisión importante para la educación de emociones y cada dominio de acción motriz está asociado con la producción de ciertos tipos de emociones.

Bibliografia: Lavega, P.; Filella, G.; Agulló, Mª. J.; Soldevilla, A.; \& March, J. (20II). Understanding emotions through games: helping trainee teachers to make decitions. Electronic Journal of Research in Educational Psychology, 9(2), 617-640.
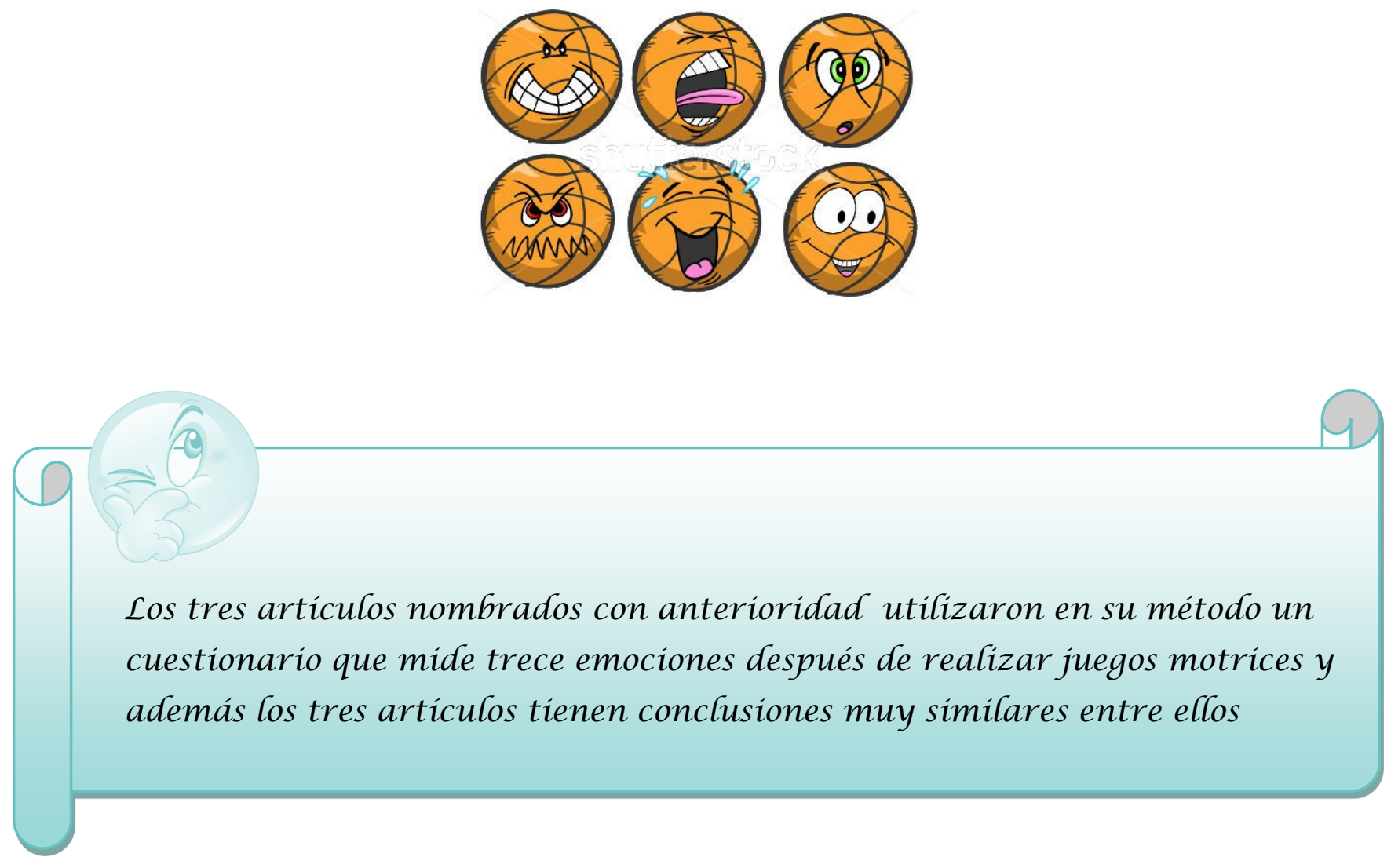


\section{Actividades}

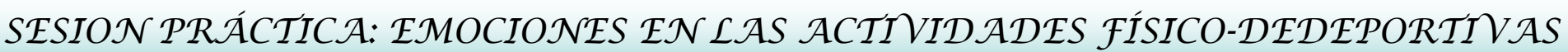
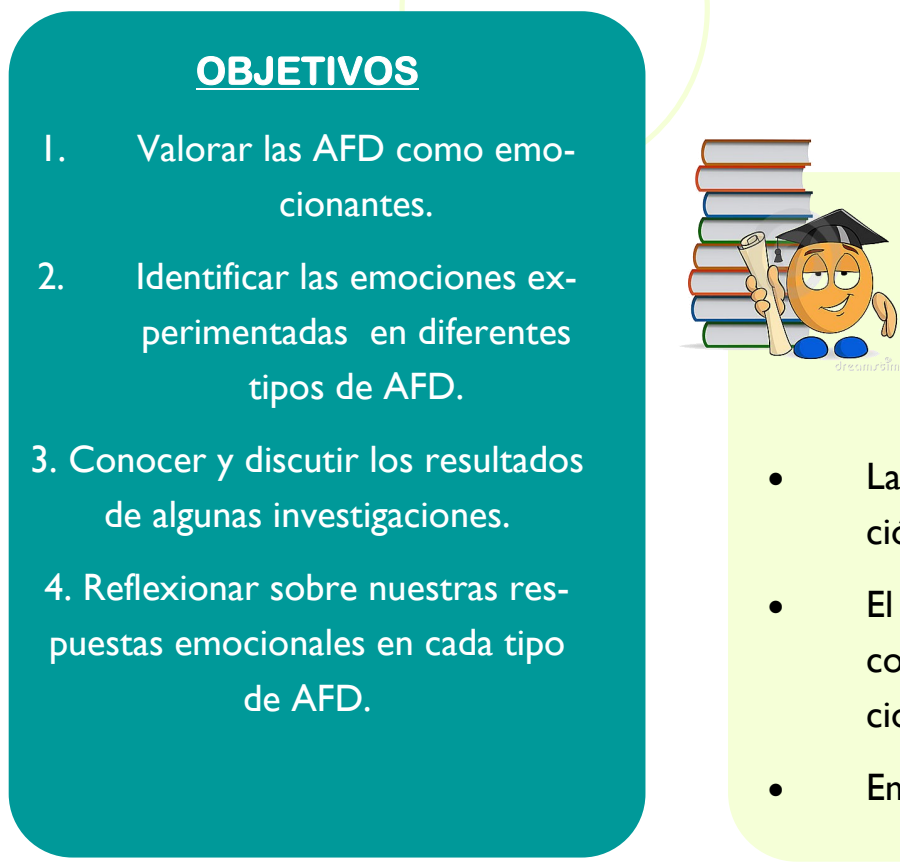

En relación con la teoría...

- La educación emocional como la raíz de la educación en valores.

- El conocimiento de las emociones en las AFD como parte del desarrollo de la Inteligencia Emocional.

- Emocionar a través de las AFD.

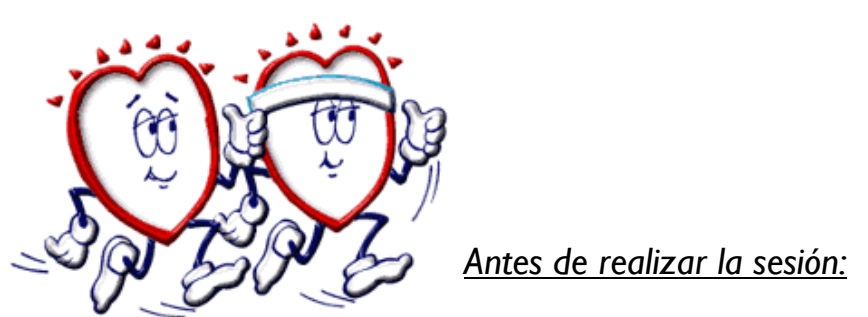

Para empezar se informó de las actividades que se llevarían a cabo. Estas estarán divididas según la clasificación praxeológica y luego se puntuarán las emociones que han despertado cada una de las actividades.

Dedicamos escaso tiempo al autoconocimiento y se puede utilizar en la actividad física como herramienta para conocernos. El puntuar emocionalmente las actividades nos servirá para reconocer estas emociones ya que es el primer paso para la inteligencia emocional.

Se realizarán ocho actividades que pueden o no desencadenar en nosotros las diferentes emociones, tanto positivas (alegría, amor, felicidad, sorpresa, empatía y compasión y por último, altruismo) como negativas (ira, miedo, ansiedad, tristeza, vergüenza y rechazo) y se puntuarán de cero a dos ( $0=\mathrm{Nada}$ I= Algo; 2=Mucho). Los niveles de emoción sentidos tras las actividades serán traspasadas al papel justo después de realizar cada una de ellas. De esta manera, se conseguirá que los alumnos expresen estas emociones justo después de haberlas vivenciado y les sea más fácil evaluarlas. 
4. Puntúa el nivel experimentado en cada juego de cada emoción de 0 a 2 ( $0=$ nada; $1=\mathrm{algo} ; 2=$ mucho)

\begin{tabular}{|c|c|c|c|c|c|c|c|c|c|c|c|c|c|}
\hline \multicolumn{2}{|c|}{\begin{tabular}{ll|} 
Situación Juego & Clases de Emociones \\
\end{tabular}} & \multicolumn{6}{|c|}{ Emociones Positivas, beneficiosas o útiles } & \multicolumn{6}{|c|}{ Emociones Negativas, periudiciales o inútiles } \\
\hline \multicolumn{2}{|c|}{\begin{tabular}{|l|} 
Nombre del juege \\
\end{tabular}} & 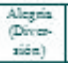 & 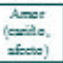 & $\begin{array}{l}\text { Folied } \\
\text { Pan } \\
\text { bienas }\end{array}$ & Ses,yeas & Engan & Almains & $\underset{\text { (Enfide) }}{\mathrm{h}}$ & $\begin{array}{l}\text { Serside } \\
\text { (Tamer) }\end{array}$ & 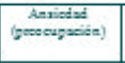 & \begin{tabular}{c|} 
Traters \\
(Funameise)
\end{tabular} & 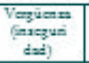 & $\begin{array}{l}\text { Rechars } \\
\text { deaymedis }\end{array}$ \\
\hline \multicolumn{2}{|l|}{$\begin{array}{l}\text { HABILIDADEN FUTBOL } \\
\text { (Psisomotor in Vistori2) }\end{array}$} & & & & & & & & & & & & \\
\hline \multirow[t]{2}{*}{$\begin{array}{l}\text { TIRA F PUNTUA } \\
\text { (Fsicomotor con Vietoriz) }\end{array}$} & Venosdor & & & & & & & & & & & & \\
\hline & \begin{tabular}{|l|} 
Perdedor \\
\end{tabular} & & & & & & & & & & & & \\
\hline \multicolumn{2}{|l|}{$\begin{array}{l}\text { CAZADEL ZORRO } \\
\text { (Oposición sin Vietoin) }\end{array}$} & & & & & & & & & & & & \\
\hline \multicolumn{2}{|l|}{$\begin{array}{l}\text { GOLPEOSSINQUE CAIGA } \\
\text { (Coopención sin Vistoniz) }\end{array}$} & & & & & & & & & & & & \\
\hline \multirow[t]{2}{*}{$\begin{array}{l}\text { TRANSPORTE BALON } \\
\text { (Cooperzción con Vietoniz) }\end{array}$} & Vexasdor & & & & & & & & & & & & \\
\hline & Perdador & & & & & & & & & & & & \\
\hline \multirow[t]{2}{*}{$\begin{array}{l}\text { PENALTIS } \\
\text { (Oposición con Vistoniz) }\end{array}$} & Vencedor & & & & & & & & & & & & \\
\hline & \begin{tabular}{|l|} 
Perdodor \\
\end{tabular} & & & & & & & & & & & & \\
\hline \multirow[t]{2}{*}{$\begin{array}{l}\text { FUTBOLIN } \\
\text { (Coopención-Oposisión con Vistoniz) }\end{array}$} & Vernosdor & & & & & & & & & & & & \\
\hline & \begin{tabular}{|l|} 
Perdedor \\
\end{tabular} & & & & & & & & & & & & \\
\hline \multirow[t]{2}{*}{$\begin{array}{l}\text { PELICUIAS } \\
\text { (Cooperzcion con vietoniz) }\end{array}$} & Vencedor & & & & & & & & & & & & \\
\hline & Perdedor & & & & & & & & & & & & \\
\hline \multicolumn{5}{|c|}{$\begin{array}{l}\text { EMOCIONESPOSITIVAS } \\
\text {-ALEGRIA: Entusiasma, euforia, excitación contento, diversión, placer, éxtasis, } \\
\text { aligeramiento, caprichoum } \\
\text {-AMOR: Afecto, cariño, ternura, simpatía, empatía, aceptación, cordialidad, } \\
\text { confianza, amabilidad, afinidad,.. } \\
\text {-FELICIDAD: Gozo, tranquilidad, paz interior, placidez, satifaccón, bianestar.u } \\
\text {-SORPRESA: Reacción por un imprevisto que puede derivar en emociones +o } \\
\text {-EMPATÍA: ponerse en el lugar de otro, percibir sus emociones. } \\
\text {-ALTRUISMO: realizar un gesto generoso sin esperar compensación }\end{array}$} & & \multicolumn{8}{|c|}{$\begin{array}{l}\text { EMOCIONESNEGATIVAS } \\
\text {-IRA: Rabia, cólera, rencor, odio, furia, indignación, enfado, calos, violencia,... } \\
\text {-MIEDO: Temor, horror, pánico, terror, desasosiego, susto, fobia. } \\
\text {-AN SIEDAD: Angusta, desesperación, inquietud, estrés, preocupación anhelo, desazón, } \\
\text {-TRISTEZA: Depresión, frustración, decepción, soledad, pena, dolor, desconsuelo,... } \\
\text {-VERGOENZA: Oulpabilidad, timidez inseguridad, vergüenza ajena, bochorno, pudor. } \\
\text {-RECHAZO. Hostilidad, desprecoo, recelo, menosprecio, asco, repugnancia, antipatí... }\end{array}$} \\
\hline
\end{tabular}

Bibliografia: Sáenz-López, P. (20/4). Apuntes inéditos de la asignatura "La educación en valores y la práctica de actividad física en colectivos en situación de desigualdad". Grado de Ciencias del Deporte. Universidad de Huelva.

\section{(O)}

Después de realizar la sesión:

La clase se puede valorar de forma positiva como satisfactoria, con momentos de descontrol breves pero predominó las risas y la alegría.

Dos compañeros que no pudieron realizar la práctica hicieron un seguimiento a otros dos para así ver su implicación desde fuera, llegamos por tanto a la conclusión de que la percepción de las emociones varía, no es lo mismo la percepción desde fuera que la que tenemos de nosotros mismos. Cada persona tiene una opinión y para nada tienen porqué coincidir, de hecho pueden llegar a ser muy dispares.

Los compañeros que han observado la práctica desde fuera han percibido más sensaciones negativas que nosotros mismos. También nos pasa por ejemplo, cuando tenemos una discusión y la contamos el cerebro nos engaña y sólo recordamos como la otra persona era la que estaba enfadada, mientras no es así ya que una discusión se produce si dos personas quieren, en cuanto una se niega la discusión termina. Todos percibimos el enfado del otro y no el de uno mismo.

Es la primera vez que hacemos algo así para medir sensaciones y nos cuesta mucho percibir nuestras propias emociones. Es importante en el deporte aunque es raro que se lleven a cabo actividades de este tipo, normalmente se usan puntualmente o solo en algunos colectivos determinados.

Hay que entrenarse para reconocer nuestras emociones porque son cruciales gestionarlas tanto en la formación como en el rendimiento. 


\title{
V. Programa de AFD en poblaciones de desigualdad
}

\author{
El deporte genera emociones
}

Carlos de Cárcer estuvo realizando tareas administrativas de la escuela de Lusaka y observó que los niños y niñas en los descansos se quedaban sin hacer nada por lo que propuso aprovechar un terreno para hacer pistas (una de fútbol y tres de voleibol), ahí pudo entablar amistad con los chavales ya que se pasaba horas jugando con ellos.

En 1999 redacto los estatutos de una asociación que se llamó "Deportistas Sin Fronteras".

En 200 I con la colaboración de Thomas Dalury que mostraba también gran interés en por el deporte en ambientes de marginación social y gracias a la financiación del Ayuntamiento de Madrid trabajaron en proyectos en Nicaragua, Sierra Leona.

La ONG pasó a llamarse "Red Deporte y Cooperación" y a partir de entonces ha desarrollado proyectos de cooperación por medio del deporte en 20 países.

Este cooperante dice que en estos países en cuanto hablas con el director de una escuela y se les menciona la palabra "deporte" se alegran y, según Carlos de Cárcer, esto surge espontáneamente por las emociones que despierta el deporte y porque se conjuga muy bien con las respuestas a otras necesidades de estos países como la educación y la salud.

El deporte es un gran conductor de relaciones humanas:

Las personas se relacionen más fácilmente.

Se vivan juntos las emociones intensas.

Es divertido (muy importante en países con conflictos y situaciones trágicas).

Un ejemplo: en los campamentos saharauis de Tinduf la gente vive en aislamiento y caen fácilmente en la apatía mientras el deporte les abre nuevas perspectivas y hace que su mente se mantenga ocupada.

En definitiva, el deporte despierta emociones fundamentales y esto se consigue a través de este programa de AFD en poblaciones en desigualdad.

Bibliografia: Red Deporte y Cooperación (I2 de Noviembre de 2014). El deporte despierta emociones. Disponible en: http://www.redeporte.org/prensa_noticia_ampliada.php?id=133 [4 de Noviembre de 2014].
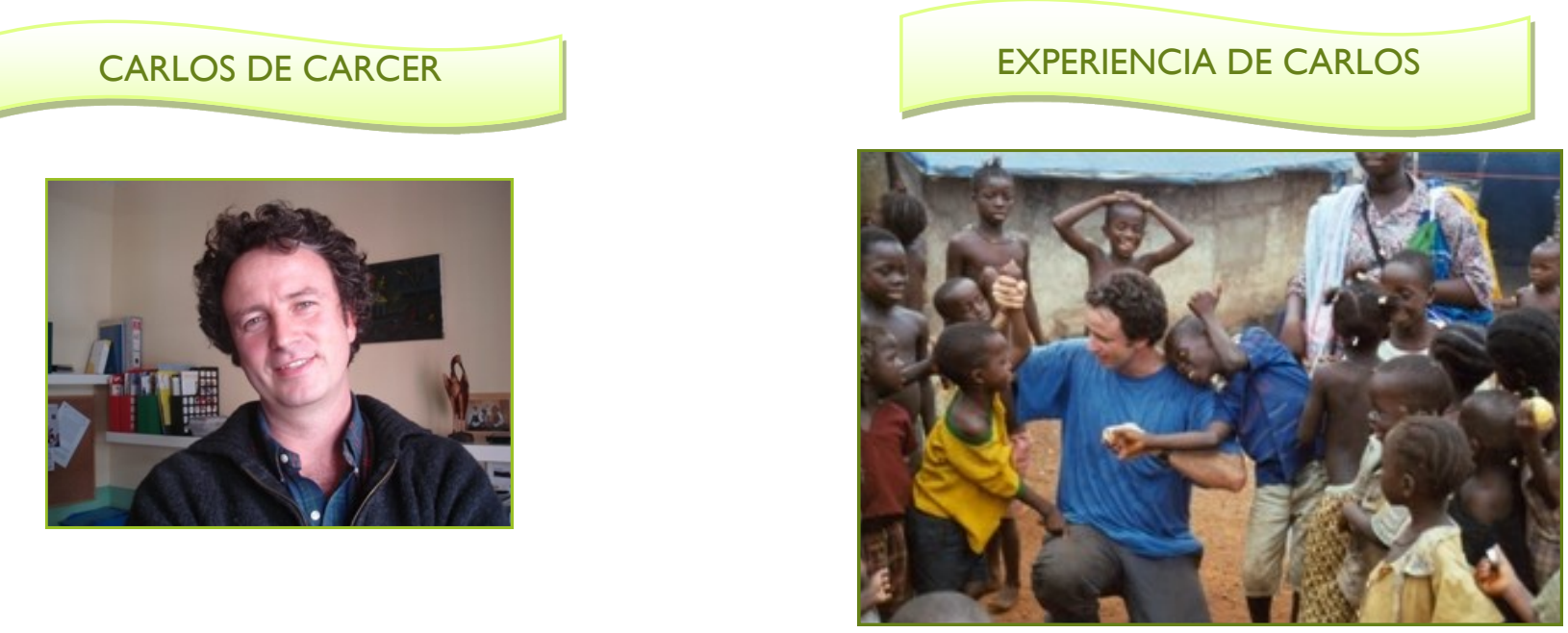


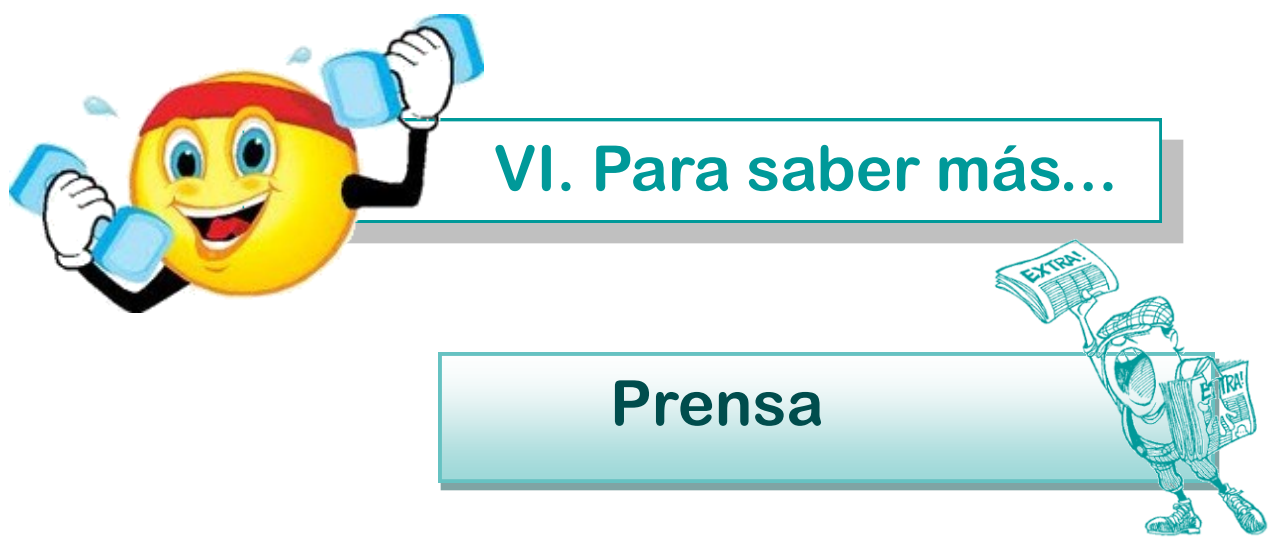

Pablo Fernández-Berrocal hace referencia en esta publicación a la inteligencia emocional, en la que según Howard Gardner existen diferentes tipos como sería la inteligencia social e inteligencia creativa.

La gestión de las emociones nos permite:

Ser más creativos e innovadores

Superar el miedo a la crítica o al fracaso

Crear confianza

Ponernos en el lugar del otro para entenderle mejor

Descubrir qué nos une a las personas más allá de las diferencias

Solucionar conflictos sin violencia y de forma constructiva

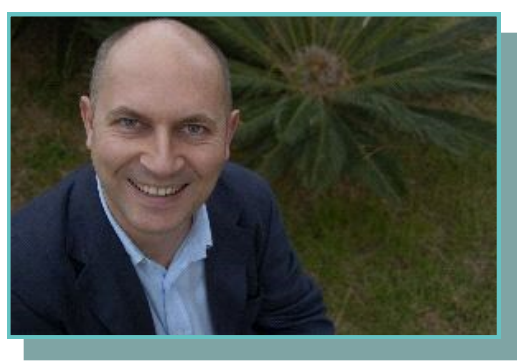

Aprovechar la fuerza que tienen emociones como la frustración

La investigación más reciente afirma que una mayor IE mejora el rendimiento académico, las relaciones sociales y el ajuste psicológico. Los científicos sociales de diferentes países han demostrado que estas inteligencias se pueden desarrollar, por lo que en nuestro país, la Fundación Botín ha puesto en marcha un Programa de Educación Responsable. Este programa confirma que se reduce la ansiedad y mejora la compresión de los niños del centro estudiado.

En Andalucía se desarrolla el proyecto INTEMO, un programa de educación emocional en adolescente donde se confirma que los niños con mayor IE consumen menos drogas, tienen menos conductas agresivas, son más empáticos y tienen una mejor salud mental.

Pablo Fernández recomienda incluir esta IE en el sistema educativo debido a los resultados de los distintos estudios que se han realizado y así, en un futuro, contar con personas sanas y equilibradas, menos agresivas, más solidarias, con iniciativa, creatividad y liderazgo, en definitiva con mejores personas.

Bibliografia: Pablo Fernández-Berrocal (26 de Noviembre 2013). La inteligencia que necesitamos. El País. Disponible en: http://elpais.com/elpais/20 I3/I I/I8/opinion/I3847870I4_634340.html [II de Noviembre de 2014].

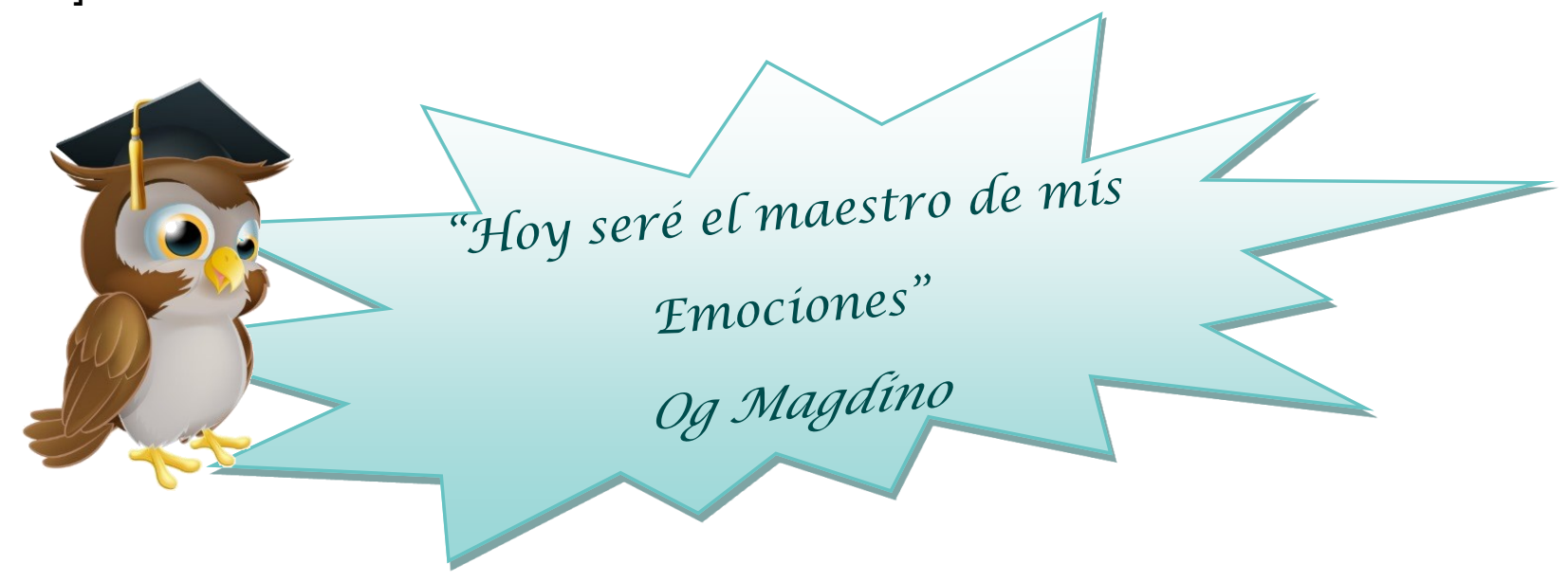




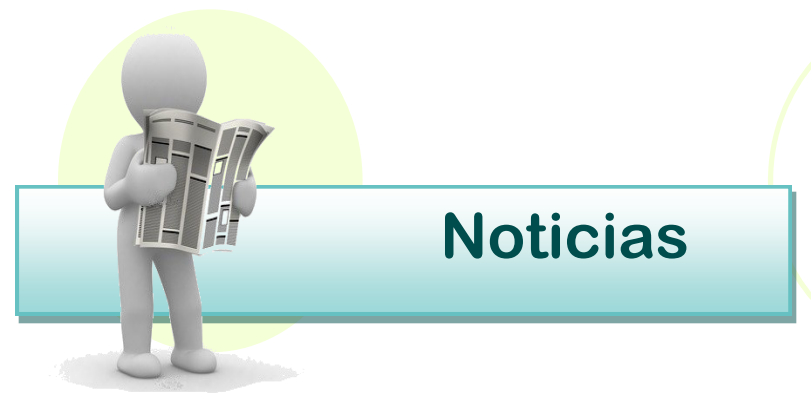

\section{Mataron a un futbolista de una pedrada en Argelia}

Es asesinado el delantero camerunés Albert Ebossé Boojongo a los 26 años por sus propios hinchas.

El equipo argelino perdió como local y sus aficionados tiraron piedras al terreno de juego impactando una de ellas en la cabeza del africano, que había marcado el único gol de su equipo $y$, además, esa mañana había sido padre. Murió en la ambulancia de camino al hospital.
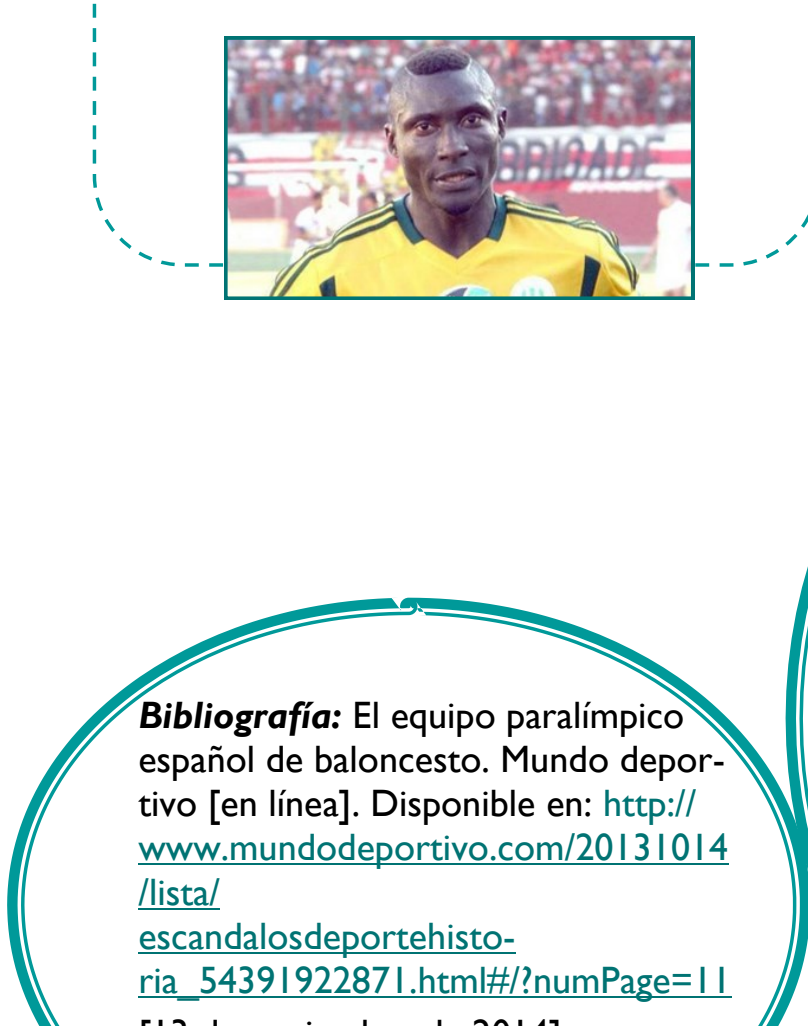

Bibliografía: El equipo paralímpico español de baloncesto. Mundo deportivo [en linea]. Disponible en: http:// www.mundodeportivo.com/20131014

ria_5439192287I.htm|\#/?numPage=I|

[ 3 de noviembre de 20I4].

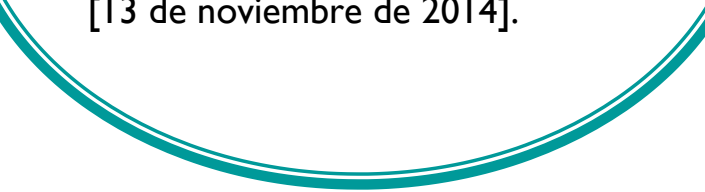

Bibliografía: Mataron a un futbolista de una pe- ', drada en Argelia. La Gaceta Deportiva [en línea].' 25 de agosto de 20/4. Disponible en: http://! www.lagaceta.com.ar/nota/604944/deportes/ mataronfutbolistapedradaargelia.html [13 de noviembre de 2014].

\section{El equipo paralímpico español de baloncesto}

El equipo de baloncesto paralímpico español ganó la medalla de oro en los Juegos Olímpicos de Sídney 2000. Pero, después de los Juegos se descubrió que 10 de los 12 jugadores del equipo no tenían ninguna discapacidad y fueron obligados a devolver sus medallas. 


\section{EI conflicto entre Tonya \\ Harding y Nancy Kerrigan}

Al inicio de los Juegos Olímpicos de Invierno en Lillehammer, la patinadora artística Nancy Kerrigan fue golpea en la rodilla en un entrenamiento. La investigación reveló que el atacante fue contratado por el exmarido de Tonya Harding una de las competidoras de Kerrigan. Harding no lo supo hasta después y mintió a los investigadores.

Al final Kerrigan quedó plata, mientras que Harding cayó hasta la octava posición, además, fue expulsada del circulo de patinaje artístico de los Estados Unidos y desde entonces ha tenido varios problemas con la justicia.

Bibliografía: El conflicto entre Tonya Harding y Nancy Kerrigan. Mundo deportivo [en línea]. Disponible en: http://www.mundodeportivo.com/20131014/ lista/escandalosdeportehistoria_5439|92287I.html\#/? numPage $=8$ [ 13 de noviembre 20I4].

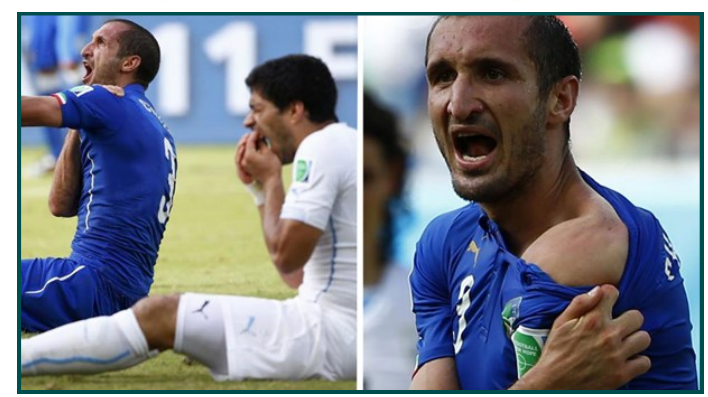

\section{¡Luis Suárez mordió en el hombro a Chiellini!}

El delantero uruguayo, después de una fantástica mano de Buffon en la mejor ocasión que tuvo para marcar ante Italia, mordió en el hombro a Chiellini en un partido del Mundial de Brasil, este último contestó a la agresión con un intento de codazo y ambos acabaron tendidos en el césped acusándose mutuamente. El árbitro no sancionó a ninguno de ellos. Luis Suarez era la tercera vez que mordía a alguien en un terreno de juego.

Bibliografía: Álvaro Olmedo (24 de junio de 2014). ¡Luis Suárez mordió en el hombro a Chiellini! Marca [en línea]. Disponible en: http:// www.marca.com/2014/06/24/futbol/ mundial// 4036339/5.html [ /3 de noviembre de 2014]. 


\section{Libros recomendados}

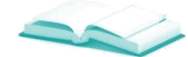

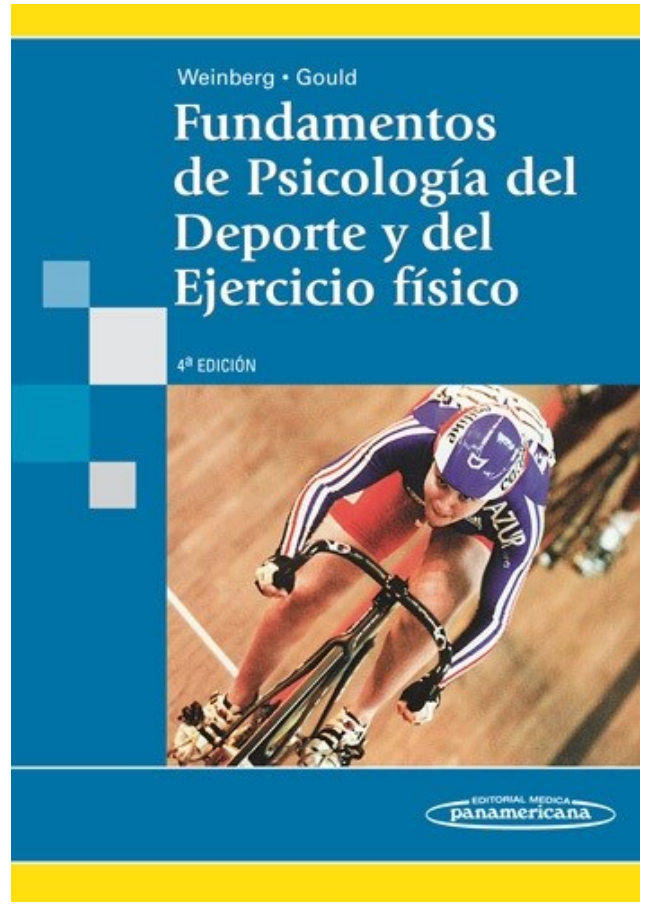

\section{Cómo potenciar} las emociones positivas

\section{y afrontar}

\section{las negativas}

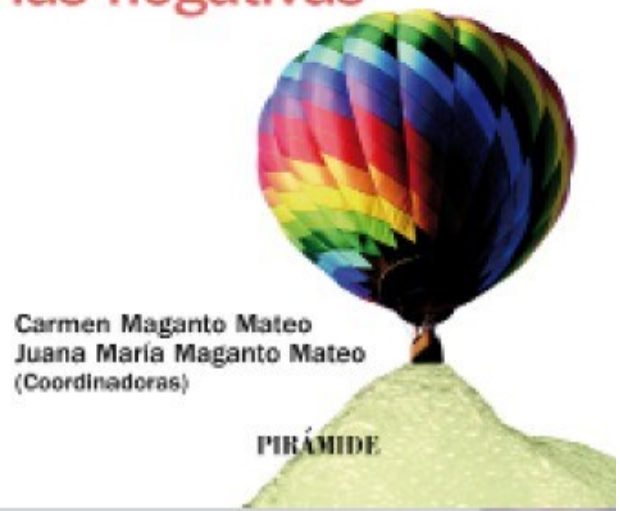

Esta edición de Fundamentos de Psicología del Deporte y del Ejercicio, sigue ofreciendo una rigurosa presentación de los conceptos centrales de esta disciplina. Brinda a los estudiantes $y$ a los profesionales que recién se inician un panorama integral dela psicología del deporte y el ejercicio, zanja la brecha entre la investigación y la práctica, transmite los principios de la práctica profesional y despierta el interés sobre el mundo del deporte y el ejercicio físico. Material actualizado sobre las últimas investigaciones y prácticas en la disciplina para que los estudiantes tomen contacto con las novedades y temas candentes de la materia. Recuadros con ejemplos prácticos, estudios de casos y anécdotas de gran actualidad para facilitar el aprendizaje de las diversas teorías y conceptos. Puntos clave que resumen la información fundamental de cada capítulo.

Las autoras de este trabajo exponen de forma clara y didáctica qué son las emociones, sus principales características y cómo funcionan en nuestra vida cotidiana. Además, explican con detalle cuáles son las principales emociones positivas y negativas, indicando cómo nos afectan y ofreciendo orientaciones para potenciar o afrontar cada una de ellas. También explican cómo es posible trabajar las emociones desde distintos puntos de vista: inteligencia emocional, salud integral, el poder de las palabras o la fuerza del pensamiento.

Las emociones nos acompañan en nuestra vida desde que nacemos. Poner nombre a las emociones es fundamentan para afrontarlas o potenciarlas. La felicidad depende de la positividad con la que vivimos los acontecimientos de cada día, y a todos nos cuesta hablar de lo que sentimos y reconocer qué nos ocurre, es como una asignatura pendiente que, por suerte, se puede aprender. 


\section{Las frases del día...}

"Los seres humanos se movilizan cuando alguien moviliza sus emociones"

Robin S. Sharma

Sin emoción no hay proyecto.

\section{Eduardo Punset}

Es muy probable que las mejores decisiones no sean frutos de una reflexión de cerebro sino del resultado de una emoción.

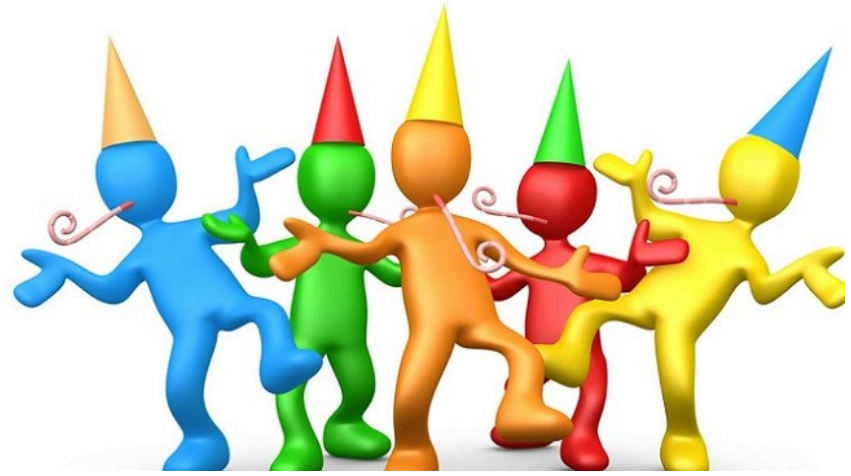




\section{Pasatiempos}

\section{Buscando mis emociones}
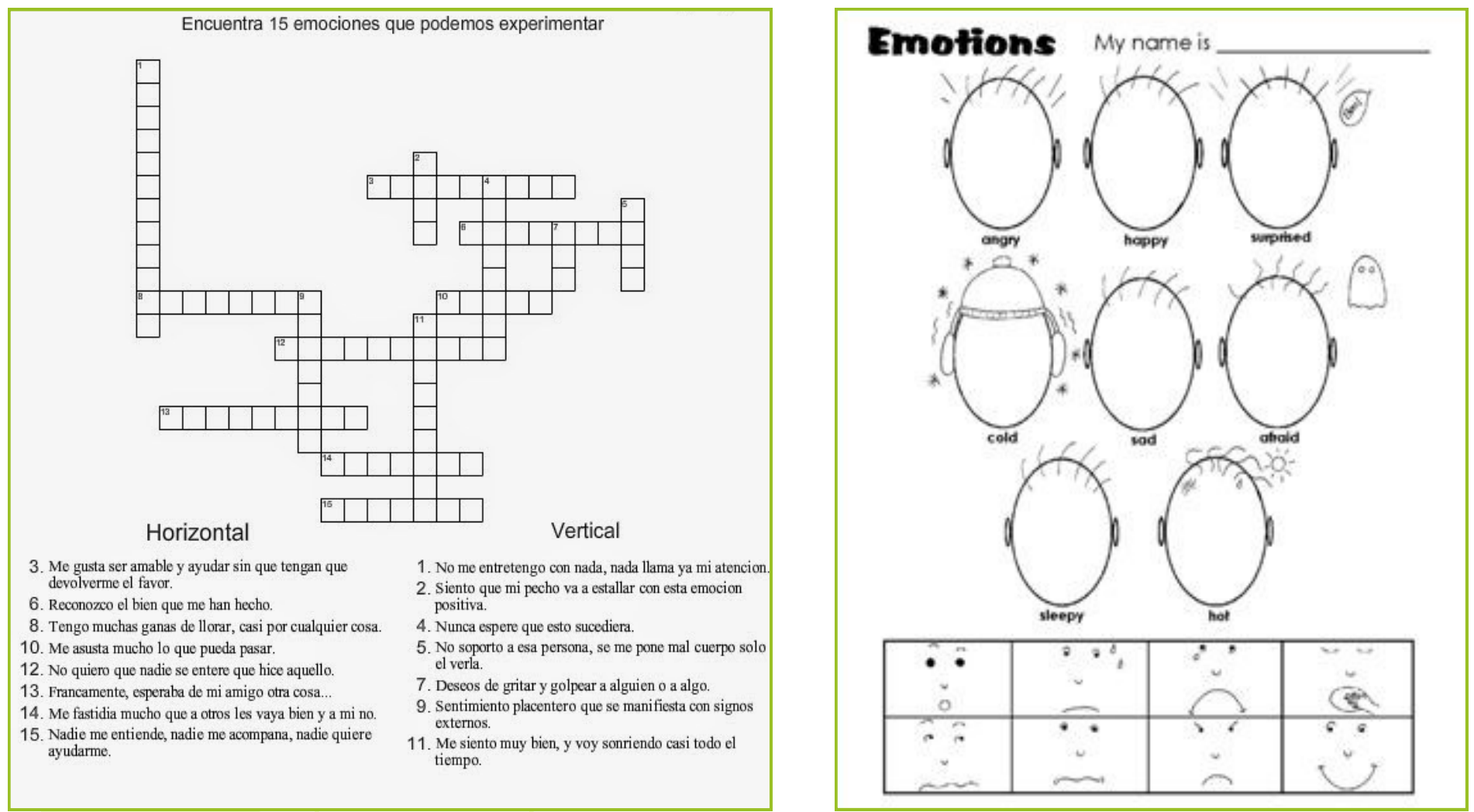

\begin{tabular}{|c|c|c|c|c|c|c|c|c|c|c|c|c|c|c|c|c|c|c|}
\hline G & $z$ & $\mathbf{H}$ & $A$ & $\mathrm{~K}$ & $x$ & D & $M$ & $F$ & $Y$ & $\mathbf{J}$ & $P$ & $x$ & $\mathbf{H}$ & & & & $\mathbf{N}$ & ALEGRIA \\
\hline I & D & D & $N$ & $\mathbf{R}$ & $\mathbf{J}$ & $z$ & 5 & $v$ & L & $\mathbf{J}$ & $\mathbf{N}$ & G & $F$ & $v$ & $Y$ & H & $\mathrm{s}$ & $\begin{array}{l}\text { ALTRUISMO } \\
\text { AMOR }\end{array}$ \\
\hline$x$ & 0 & $E$ & $F$ & 0 & 0 & G & 0 & A & $A$ & H & $P$ & $\mathrm{~F}$ & B & $A$ & $\overline{\mathbf{N}}$ & 0 & $\mathbf{P}$ & ANSIEDAD \\
\hline$x$ & L & $\mathbf{R}$ & $\mathrm{T}$ & $E$ & $\mathrm{~F}$ & $\theta$ & $P$ & 0 & J & 0 & $M$ & $\mathrm{C}$ & L & $Y$ & $\mathbf{R}$ & $\mathbf{N}$ & $\mathbf{H}$ & EMPATIA \\
\hline$F$ & $Q$ & 0 & A & 0 & $\mathbf{L}$ & G & $\hat{N}$ & $\mathbf{R}$ & $\mathbf{R}$ & $P$ & $\theta$ & $\mathrm{E}$ & $v$ & $P$ & $\theta$ & $\mathrm{K}$ & I & FELICIDAD \\
\hline $\mathrm{F}$ & G & $M$ & $\mathrm{~K}$ & $Y$ & L & I & $M$ & B & $A$ & $\mathrm{~s}$ & G & I & $\mathbf{R}$ & I & $\mathbf{N}$ & $\hat{N}$ & $v$ & $\begin{array}{l}\text { MIEA } \\
\text { MIEDO }\end{array}$ \\
\hline$A$ & $\mathrm{~N}$ & $A$ & $F$ & $\theta$ & u & $\hat{N}$ & C & 5 & $z$ & $\mathbf{R}$ & L & E & $\theta$ & $v$ & $\hat{\mathbf{N}}$ & $P$ & $\mathrm{~K}$ & RECHA \\
\hline$F$ & $\mathbf{N}$ & $\mathbf{N}$ & $M$ & A & W & $z$ & $\theta$ & I & I & G & 5 & C & B & 0 & $\mathrm{R}$ & $\mathrm{L}$ & $A$ & SORPRESA \\
\hline $\mathbf{J}$ & u & 5 & $\mathbf{N}$ & $\mathbf{H}$ & $\mathbf{T}$ & $\mathrm{L}$ & $z$ & $A$ & D & $A$ & $z$ & B & $\mathbf{T}$ & $P$ & $\mathbf{J}$ & $\mathrm{T}$ & $Y$ & $\begin{array}{l}\text { VERGUENZA } \\
\text { SELA }\end{array}$ \\
\hline$M$ & $M$ & $\mathbf{N}$ & I & $\mathrm{C}$ & $v$ & $\mathbf{T}$ & B & $\hat{N}$ & $M$ & $A$ & $Q$ & $M$ & C & L & $T$ & $\hat{\mathbf{N}}$ & $\mathbf{R}$ & \\
\hline U & $\mathbf{R}$ & $A$ & $Y$ & $E$ & $\theta$ & $\mathbf{T}$ & 5 & I & $\mathrm{T}$ & $\mathbf{T}$ & D & $x$ & I & $\mathrm{E}$ & w & $\mathbf{R}$ & $E$ & \\
\hline $\mathbf{N}$ & $\mathbf{N}$ & $F$ & C & $\mathbf{R}$ & D & 0 & $\mathbf{H}$ & $\mathbf{R}$ & $v$ & $\mathrm{E}$ & $\mathbf{R}$ & $\mathbf{G}$ & U & $E$ & $\mathbf{N}$ & $z$ & $A$ & \\
\hline$F$ & $A$ & $\mathbf{R}$ & I & I & $v$ & $A$ & I & H & $\mathrm{u}$ & L & $\theta$ & $v$ & $z$ & $\mathbf{J}$ & D & $\theta$ & $\mathrm{K}$ & \\
\hline G & $\mathbf{J}$ & $M$ & B & $\mathrm{T}$ & H & 5 & D & $E$ & $M$ & $P$ & $A$ & $\mathbf{T}$ & I & $A$ & D & 0 & $\mathbf{G}$ & \\
\hline$v$ & B & $\mathbf{R}$ & $A$ & $\mathbf{R}$ & $\mathbf{T}$ & $\mathrm{E}$ & D & 0 & $P$ & $\mathbf{N}$ & $\mathbf{N}$ & $\mathrm{C}$ & $F$ & $\mathbf{J}$ & $\mathbf{L}$ & 0 & $F$ & \\
\hline$Y$ & I & 0 & W & $E$ & $\mathrm{E}$ & $Y$ & $\mathbf{T}$ & $\mathbf{J}$ & D & C & $\mathbf{T}$ & $\mathbf{N}$ & $P$ & $\theta$ & $Q$ & $P$ & $\theta$ & \\
\hline$M$ & $\mathbf{R}$ & $A$ & $z$ & $P$ & $\mathbf{R}$ & $\hat{\mathbf{N}}$ & $v$ & $A$ & L & $\mathbf{T}$ & $\mathbf{R}$ & u & I & 5 & $M$ & 0 & $\mathrm{~K}$ & \\
\hline U & $E$ & $A$ & $\mathbf{H}$ & $A$ & $E$ & $\mathbf{R}$ & B & $\mathbf{G}$ & L & C & $\hat{\mathbf{N}}$ & $v$ & 5 & $z$ & $\mathrm{~L}$ & $Y$ & $\mathbf{H}$ & \\
\hline
\end{tabular}




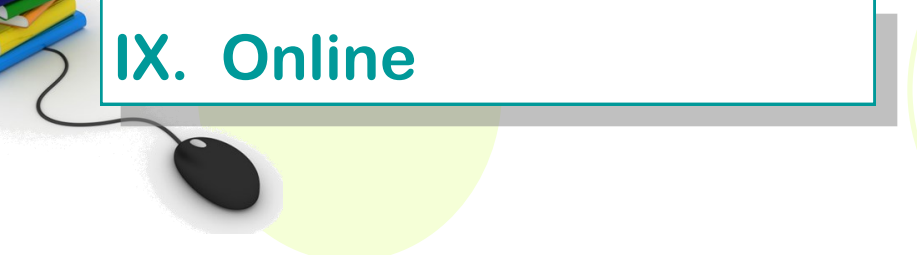

VIDEOS

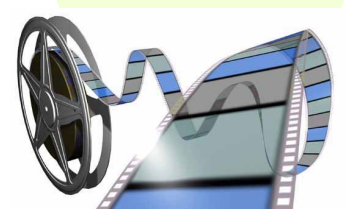

- Documental legendarios (2012, 16 de junio). Deporte y emociones. Disponible en: http://www.youtube.com/watch?v=TFpWsaKOhGs

- Inteligencia emocional en el deporte (2011, 29 de Agosto). Disponible en: http:/l www.youtube.com/watch?v=8X--IRqsXms

- Cattell psicólogos en Murcia (2013, 20 de Septiembre). Psicología del deporte de alto rendimiento, el poder de la mente. Peters, S. Disponible en: http:/l www.youtube.com/watch?v=RGyrfpqn2EI.

- TVE “Informe Semanal” (2010, 12 de Junio). TVE- Rafael Nadal, el poder de la mente. Disponible en: http://www.youtube.com/watch?v=V-SIvOxcZmc.

- Redes- Aprender a gestionar las emociones (2013, 27 de Junio). Punset,E. Disponible en: http://www.youtube.com/watch?v=EEydoHsmrXs

\section{WEBSITES}

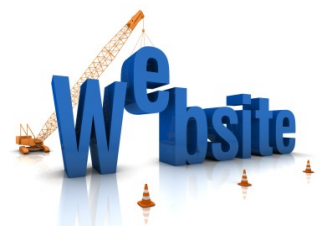

- Educación emocional y movimiento (2011, 20 de Septiembre), [en línea]. Pellicer, I. Disponible en: http://educacionemocionalymovimiento.blogspot.com.es/2011/09/ educacion-fisicaemocional.html

- Vivir salud y mujer (2014, 19 de Agosto), [en línea]. Ramirez, F. Disponible en: http:/l vivirsalud.imujer.com/6875/el-deporte-ideal-para-aliviar-las- emociones

- Web consultas (2014, 5 de Noviembre), [en línea]. Disponible en: http:/l www.webconsultas.com/mente-y-emociones/test-de-psicologia/test-sabescontrolar-tus-emociones-11432 


\section{Conclusiones}

\section{EL DEPORTE GENERA EMOCIONES}

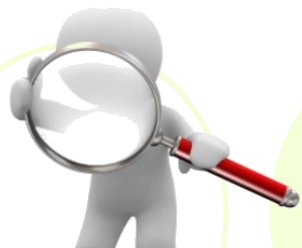

\section{EI deporte, en general, genera más emociones positivas que negativas.}

III. Nos cuesta reconocer nuestras emociones en especial las negativas.

IV. En función del dominio que tengas de la actividad se tendrán mejores o peores sensaciones.

V. A veces un sujeto ajeno puede percibir más las emociones que la propia persona.

VI. Las actividades con competición generan mayor grado de emoción, la competición juega con la intensidad emocional.

VII. Las actividades en el medio natural generan algunas emociones, como el miedo, pero es bueno conocer esta emoción y saber gestionarla porque nos será útil a lo largo de la vida.

VIII. Todas las emociones son útiles ya que al conocerlas podremos gestionarlas de la manera más adecuada y esto es un reto de nosotros como educadores.

IX. Diferencias de las emociones según las actividades, ya sean individuales o colectivas. Las actividades colectivas generan más emociones.

X. El altruismo apenas existe en el deporte de competición porque se premia todo lo contrario y sería de gran utilidad que se diera el altruismo en el alto rendimiento ya que servirían como ejemplo los deportistas y los niños copiarían esas conductas. Nosotros como educadores tenemos que tener acciones altruistas para enseñar con el ejemplo. 
Alonso, J.l., Gea, G., \& Yuste, J.L. (2013). Formación emocional y juego en futuros docentes de educación física. Revista Electrónica Interuniversitaria de Formación del Profesorado, 16(I), 97-108.

http://www.aufop.com/aufop/uploaded_files/articulos/I375389683.pdf

Lavega, P.; Aráujo, P., y Jaqueira, A. R. (2013). Teaching motor and emotional competencies in university students. Cultura Ciencia y Deporte, 8(22), 5-15.

http://ccd.ucam.edu/index.php/revista/issue/view/48

Lavega, P.; Filella, G.; Agulló, Mª. J.; Soldevilla, A.; \& March, J. (20II). Understanding emotions through games: helping trainee teachers to make decitions. Electronic Journal of Research in Educational Psychology, 9(2), 617640. http://www.investigacion-psicopedagogica.com/revista/articulos/24/english/Art_24_519.pdf.

Red Deporte y Cooperación (12 de Noviembre de 2014). El deporte despierta emociones. Disponible en: http://www.redeporte.org/prensa_noticia_ampliada.php?id=|33 [4 de Noviembre de 2014].

Pablo Fernández-Berrocal (26 de Noviembre 2013). La inteligencia que necesitamos. El País. Disponible en: http://elpais.com/elpais/2013/I I/I8/opinion/I3847870I4_634340.html [II de Noviembre de 20I4].

Mataron a un futbolista de una pedrada en Argelia. La Gaceta Deportiva [en línea]. 25 de agosto de 2014. Disponible en: http://www.lagaceta.com.ar/nota/604944/deportes/mataronfutbolistapedradaargelia.html [13 de noviembre de 2014].

El equipo paralímpico español de baloncesto. Mundo deportivo [en línea]. Disponible en: http:// www.mundodeportivo.com/20131014/lista/escandalosdeportehistoria_5439192287I.html\#/?numPage=II [ 13 de noviembre de 2014].

El conflicto entre Tonya Harding y Nancy Kerrigan. Mundo deportivo [en línea]. Disponible en: http:// www.mundodeportivo.com/20131014/lista/escandalosdeportehistoria_5439192287/.htm|\#/?numPage=8 [13 de noviembre 2014].

Álvaro Olmedo (24 de junio de 2014). ¡Luis Suárez mordió en el hombro a Chiellini! Marca [en línea]. Disponible en: http://www.marca.com/20/4/06/24/futbol/mundial/I4036339/5.html [13 de noviembre de 2014].

Gould, D. (2010). Fundamentos de psicología del deporte y del ejercicio fisico (4 ED). Panamericana.

Maganto Mateo, J.M. (2010). Como potenciar las emociones positivas y afrontar las negativas. Piramide.

Rothbard, M (20I2). Instituto Mises Hispano [en línea]. Praxeología: la metodología de la economía austriaca. Disponible en: http://www.miseshispano.org/2012/08/praxeologia-la-metodologia-de-la-economia-austriacal [Consulta: 2014, 30 de Noviembre] 
Documental legendarios (2012, 16 de junio). Deporte y emociones. Disponible en: http:// www.youtube.com/watch?v=TFpWsaKOhGs

Inteligencia emocional en el deporte (201 I, 29 de Agosto). Disponible en: http://www.youtube.com/ watch? $=8 X--\mid R q s X m s$

Cattell psicólogos en Murcia (2013, 20 de Septiembre). Psicología del deporte de alto rendimiento, el poder de la mente. Peters, S. Disponible en: http://www.youtube.com/watch?v=RGyrfpqn2El.

TVE “Informe Semanal” (2010, 12 de Junio). TVE- Rafael Nadal, el poder de la mente. Disponible en: http://www.youtube.com/watch?v=V-SlvOxcZmc.

Redes- Aprender a gestionar las emociones (2013, 27 de Junio). Punset,E. Disponible en: http:// www.youtube.com/watch? $v=E E y d o H s m r X s$

Educación emocional y movimiento (201 I, 20 de Septiembre), [en línea]. Pellicer, I. Disponible en: http://educacionemocionalymovimiento.blogspot.com.es/20I I/09/educacion-fisicaemocional.html

Vivir salud y mujer (2014, 19 de Agosto), [en línea]. Ramirez, F. Disponible en: http:// vivirsalud.imujer.com/6875/el-deporte-ideal-para-aliviar-las- emociones

Web consultas (2014, 5 de Noviembre), [en línea]. Disponible en: http://www.webconsultas.com/mente-yemociones/test-de-psicologia/test-sabes-controlar-tus-emociones-I I 432

Checa Esquiva, I., Cantón Chirivella, E., et Espejo Tort, B. (2 de Octubre 20I3). Bidimensionalidad de las emociones en deporte: construcción y validación de un instrumento de evaluación. Anuario de Psicología Clinica y de la Salud, Volumen 09, Paginas 77 a 79. Disponible en: http://institucional.us.es/apcs/doc/ APCS_9_esp_77-79.pdf [II de Noviembre de 2014]

Palumbo, P., Medrano, L., Lussenhoff, F., Gonzalez, J. et Curarello, A. (Noviembre 20I I). Emociones positivas y negativas en futbolistas de alto rendimiento. Psiensia revista latinoamericana de ciencia psicológica, volumen 3. Disponible en: http://dialnet.unirioja.es/servlet/articulo?codigo=4390365 [I I de Noviembre 20I4]

Rebollo González, J.A. (20/3). La educación emocional en el animador deportivo. Revista de Educacion, Motricidad e Investigacion, paginas 191-195. Disponible en: http://rabida.uhu.es/dspace/bitstream/ handle/I0272/8058/La_educacion_emocional_animador_deportivo.pdf?sequence=2 [ 12 de Noviembre 2014]

Sáenz-López, P. (20I4). Apuntes inéditos de la asignatura "La educación en valores y la práctica de actividad física en colectivos en situación de desigualdad”. Grado de Ciencias del Deporte. Universidad de Huelva. 